\section{Root Dynamics of Apple Rootstocks in a Replanted Orchard}

\author{
Shengrui Yao, Ian A. Merwin', and Michael G. Brown \\ Department of Horticulture, Cornell University, Ithaca, NY 14853
}

Additional index words. Malus $\times$ domestica, minirhizotron, boroscope, apple replant disease, root demography, root turnover, methyl bromide, soil fumigation, root disease biocontrol

\begin{abstract}
Root observations in situ with a rhizotron camera enabled us to compare the performance of apple (Malus $\times$ domestica Borkh.) trees on 3 rootstock clones planted in a New York orchard with a history of apple replant disease. Visual observations were conducted in situ at monthly intervals during 2 growing seasons through minirhizotron tubes for trees grafted onto 3 rootstocks: M.7 (M.7), Geneva 30 (G.30), and CornellGeneva 6210 (CG.6210). There were 3 preplant soil treatments (fumigation, compost amendment, and untreated checks) and 2 tree planting positions (within the old tree rows or in the old grass lanes of the previous orchard at this site). Preplant soil treatments and old-row versus grass-lane tree planting positions had no apparent influence on root systems, whereas rootstock clones substantially influenced root growth and demography. New root emergence was suppressed during the first fruit-bearing year (2004) on all 3 rootstock clones compared with the previous nonbearing year (2003). A root-growth peak in early July accounted for more than $50 \%$ of all new roots in 2003 , but there was no midsummer root-growth peak in 2004. The median lifespan for roots of CG.6210 was twice that of G.30 and M.7 in 2004. Also, CG.6210 had more roots below $30 \mathrm{~cm}$ depth, whereas M.7 had more roots from 11 to $20 \mathrm{~cm}$ depth. Trees on CG.6210 were bigger, yielded more fruit, and had the highest yield efficiency in the third year after planting compared with trees on G.30 and M.7 rootstocks. Crop load appeared to inhibit new root development and changed root-growth dynamics during the first bearing year, with a resurgence in new root growth after fruit was harvested in October 2004. Rootstock genotype was the dominant influence on root lifespan and distribution in this study, whereas preplant soil fumigation, compost amendments, and replanting positions had little apparent impact on root characteristics despite their influence on above-ground tree growth and yield.
\end{abstract}

Apple replant disease (ARD) occurs in many fruit-growing regions around the world (Mai and Abawi, 1981), but its etiology varies across geographic regions and there is no consistently effective method for managing this problem (Merwin et al., 2001). Substantial economic losses resulting from ARD have been reported in most apple production regions (Geldart, 1994), and methyl bromide has been the most widely used soil fumigant for ARD control (Mai and Abawi, 1981; McKenry et al., 1994). Because of negative environmental impacts, most methyl bromide uses will soon be prohibited. Alternative soil fumigants have often been ineffective in New York orchards, and more reliable methods for controlling ARD are needed as fruit growers renovate and replant orchards (Merwin et al., 2001).

Apple rootstocks with intrinsic resistance or tolerance to ARD could provide a useful method for managing this soilborne disease,

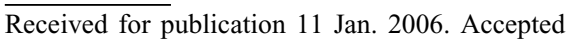
for publication 3 Apr. 2006. This research was supported in part by USDA-IREE Methyl Bromide Alternatives projects NYC-145560 and 145-530 and by CSREES project NYC 145409 . We thank Drs. Lailiang Cheng and Alan Lakso for critical reviews of the manuscript. Journal article HCS $01-390$.

${ }^{1}$ To whom correspondence should be addresssed; e-mailim13@cornell.edu.
}

and recent reports have indicated that some Malus species or new rootstock clones of the Cornell-Geneva series may be relatively tolerant of ARD (Isutsa and Merwin, 2000; Leinfelder and Merwin, 2006; Wilton, 2002). Root-system traits are presumably important in both above- and below-ground performance of trees on different rootstock genotypes. Monitoring root phenology and morphology, demography, and distribution under trees grafted on different clonal rootstocks could thus provide useful information about rootstock resistance or tolerance to ARD and practical strategies for controlling this problem.

Plant species, root diameter, rooting depth son, and environmental factors all influence root survival (Baddeley and Watson, 2005; Hendrick and Pregitzer, 1992 and 1993; Wells and Eissenstat, 2001 and 2003). Median root lifespan of citrus could be as long as 300 days and that of apple could be as short as 30 days (Eissenstat et al., 2000). For newly introduced apple rootstocks, there is little published information about their root-system characteristics. In this report, we describe an orchard experiment comparing apple tree performance on 3 clonal rootstocks in different preplant soil treatments and tree planting positions at a replant site. Our main objective was to determine the effects of these 3 factors on below-ground root characteristics and symptoms of apple replant disease. and age, mycorrhizal fungi colonization, sea-

\section{Preplant soil treatments}

The trees for this study were planted in November 2001 at a site where apples had been grown continuously since 1910. The soil was a silty clay loam (mixed, mesic Udic Hapludalf) with a root-restrictive layer at approximately $40 \mathrm{~cm}$ depth. The previous old trees were removed in September 2001, and 3 preplant soil treatments were applied in replicate blocks perpendicular to the previous tree rows: 1) fumigation with Telone $\mathrm{C}-17$ (Dow AgroSciences, Indianapolis, IN), composed of 1,3 dichloropropene $(78 \% \mathrm{v} / \mathrm{v})$ and chloropicrin $(17 \% \mathrm{v} / \mathrm{v})$, shank injected at a depth of $25 \mathrm{~cm}$ and a rate of $400 \mathrm{~L}$ per treated ha; 2) compost amendments at a rate of $984 \mathrm{~kg}$ per treated ha, incorporated into the soil to a depth of $25 \mathrm{~cm}$; and 3) nontreated control plots. An additional experimental preplant factor was tree replanting position either within the old tree rows or within the grass lanes of the previous orchard. Complete descriptions of the preplant treatments and our experimental design were reported by Leinfelder and Merwin (2006) and Rumberger et al., (2004).

\section{Rootstock clones and replanting arrangement}

The replant trees were 'Royal Empire' that had been custom propagated for this study by Wafler Nursery (Wolcott, N.Y.), on 3 rootstock clones: M.7 (M.7), CornellGeneva 6210 (CG.6210), and Geneva 30 (G.30). We conducted monthly root observations for 3 replicate trees on each rootstock in each of the 3 preplant soil treatments and 2 replanting positions (old tree rows vs. grass lanes) during 2 consecutive years.

\section{Minirhizotron tube installation and root observations}

Fifty-four 1-m-long by 5-cm-diameter transparent polycarbonate minirhizotron observation tubes were installed into snugfitting augured holes in July 2002. There was one tube per tree in 3 replicate observations for each rootstock, preplant soil treatment, planting position combination (i.e., 3 tubes $x$ 3 rootstocks $\times 3$ preplant soil treatments $\times 2$ planting positions $=54$ observation tubes). The tubes were tamped diagonally into the soil at $45^{\circ}$ angles, approximately $30 \mathrm{~cm}$ from the trunks and parallel to the tree row. To increase the sample size, we observed roots in 3 contiguous visual sectors toward the tree base within each tube: one oriented vertically (at $0^{\circ}$ ) in the radial tube cross section, another at $45^{\circ}$, and a third at $90^{\circ}$. The lower ends of tubes were sealed with neoprene stoppers, silicon gel and caps, and the above-ground portions of each tube were coated with thick black paint on the outside, sealed with a removable rubber stopper, and covered with inverted cans to exclude light and moisture. Permanent marks were etched on the outer lips of tubes so that we could align the camera with reference points on each tube to ensure identical locations for sequential observations of each visual sector and depth. 
To allow the soil/root/tube interface zone to recuperate from initial disturbance incited by boring holes and installing observation tubes, we waited for 10 months after tube installation in midsummer of 2002 before recording the first root observations in 2003. During the next 2 growing seasons, visual observations were recorded with a Minirhizotron camera (model BTC-II; Bartz Technology Corp., Santa Barbara, CA) in all 3 directions from 1 to $40 \mathrm{~cm}$ depth, on 21 May, 7 July, 22 August, and 20 October during 2003, and at monthly intervals from 25 May until 25 October during 2004.

\section{Root observation and classification}

The number, color, location, diameter, and date of first appearance and disappearance of all roots in each tube were recorded with RooTracker software (Duke University, Durham, N.C.) and tabulated for each minirhizotron observation. Roots observed for the first time were recorded as new roots, but only those that totally decomposed or disappeared were tabulated as dead roots, because roots sometimes turned brown and sloughed off outer tissue layers but then persisted and produced new lateral roots. Root diameter was therefore measured when each root first appeared. From these observational data, we calculated the cumulative number of roots per tree each year (live and dead), the total number of newly emerged and older live roots for each observation, root distribution at each depth interval, and median root lifespan (the time elapsed when $50 \%$ of roots from an initial cohort had died or disappeared) for each year.

\section{Orchard management}

Tree management practices were typical of commercial apple orchards in the northeastern United States. A hard fescue turfgrass (Festuca duriuscula) was maintained in the drive lanes by monthly mowing, and glyphosate herbicide was applied at a rate of $3.0 \mathrm{~kg}$ a.i. ha ${ }^{-1}$ in May and July annually to eliminate weeds in a $1.5-\mathrm{m}$ wide strip centered on the tree rows. Arthropod and disease pests were controlled according to published guidelines used in most New York orchards (Agnello et al., 2002). Rainfall was above normal during the 2 years of this study, and trickle irrigation was available but not applied during 2003 or 2004.

\section{Tree growth and performance}

The annual increase in trunk diameter at $45 \mathrm{~cm}$ above ground, central leader extension growth, and lateral branch extension were measured each year; in the first bearing year (2004), fruit counts and yield data were recorded for every tree. Soil nutrient availability and foliar nutrient content were also determined each year using standard methods (Stiles and Reid, 1991).

\section{Statistical methods and data analyses}

The treatment arrangement and randomization of rootstocks and preplant soil factors comprised 2 overlapping Latin Squares, enabling us to test 3 different factors at once. Each tree was an experimental unit, uniquely defined by its block, preplant soil treatment, rootstock, and planting position. The preplant soil treatments, rootstocks, and positions were fixed effects and blocks were random effects. All of the trees in one planting position (old grass lane or old tree row) composed one of the Latin Squares, and all of the trees in the opposite position composed the second Latin Square. Because root systems were observed repeatedly in the same treatments over 2 years, the root counts were analyzed as a repeated measures analysis of variance model at $P=0.05$ (Statview v. 5.02; SAS, Cary, N.C.). Root survival/mortality was analyzed with Cox's proportional hazards regression model as described in Wells and Eissenstat (2001).

\section{Results}

Like in most other minirhizotron studies of tree roots, the number of roots observed per tube was highly variable with very few roots in most viewing locations. The full analysis of variance indicated that there were
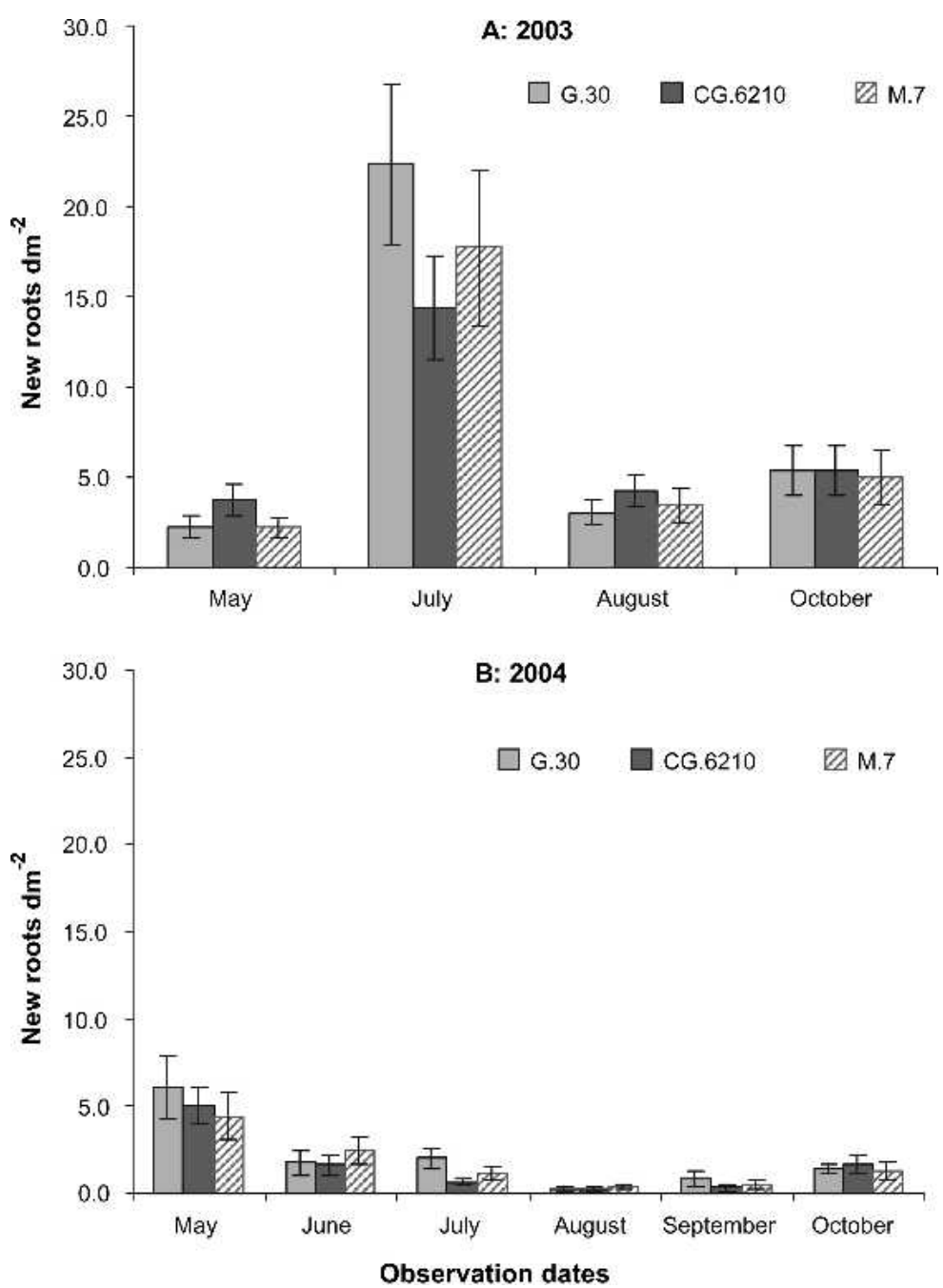

Fig. 1. Counts of new root emergence on each observation date for the rootstocks CG.6210, G.30, and M.7 in 2003 (A) and 2004 (B). Error bars are standard error of mean for $n=18$ 

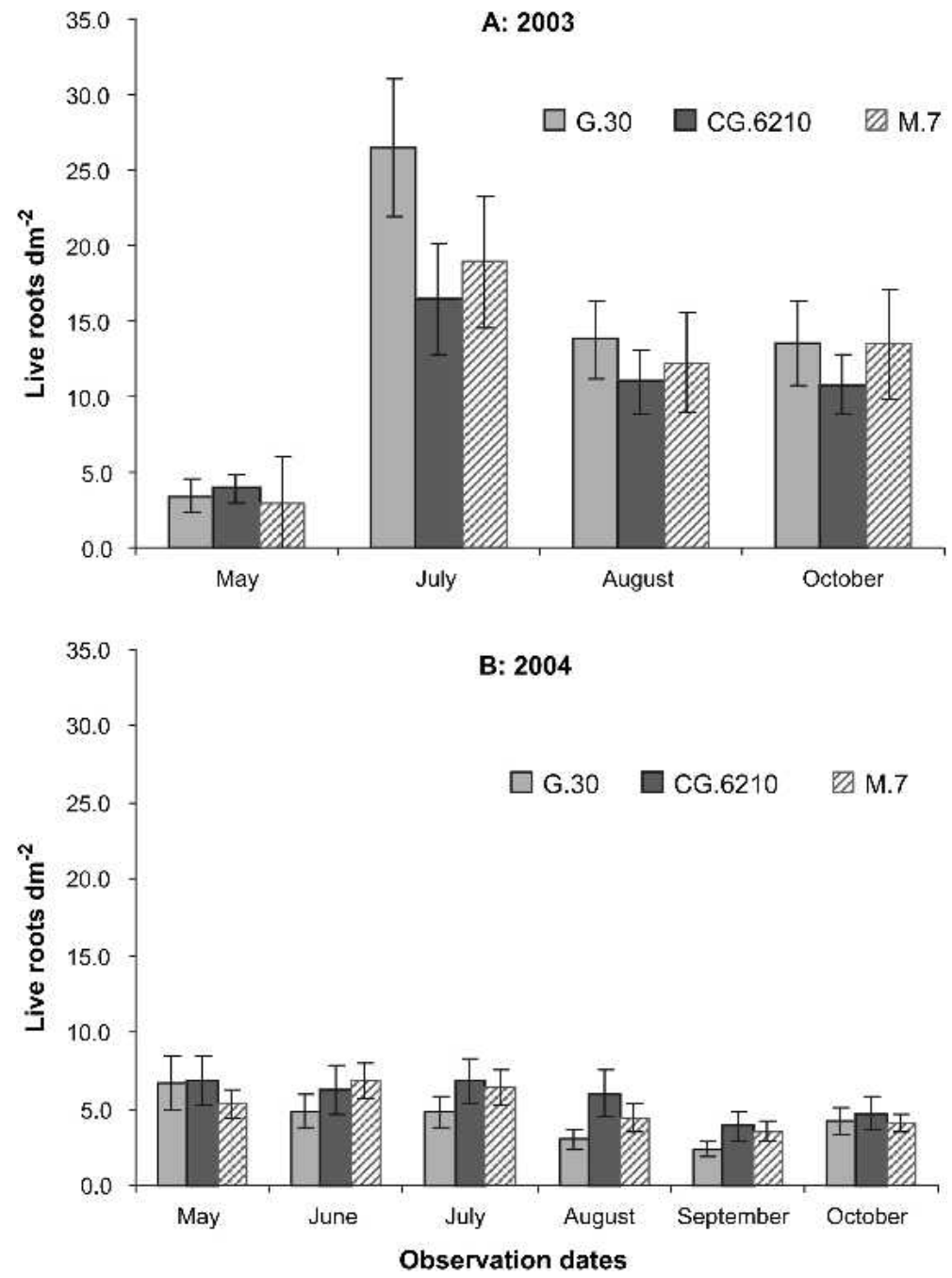

Fig. 2. Total number of live roots (new + older) observed per rhizotron tube for the rootstocks CG.6210, G.30, and M.7 in an apple replant site during 2003 and 2004. Error bars are standard error of mean for $\mathrm{n}=18$.

rootstock across the various preplant soil treatments and site factors.

\section{Live root counts over time}

Considering aggregate trends over time, the number of live roots per tree for all 3 rootstocks was greater in 2003 than in 2004 (Table 1). The average number of roots per tree (tube) actually peaked at 20.62 live roots per $\mathrm{dm}^{2}$ observation area in July 2003 (the second year after planting), declined to a low point of 3.62 roots per $\mathrm{dm}^{2}$ just before the first crop was harvested in early October 2004, and rebounded to 4.83 roots per $\mathrm{dm}^{2}$ in late October 2004 after harvest.

\section{New root emergence in 2003 and 2004}

For all of the rootstock clones, there was a major new root emergence event between May and July 2003, after which the number of new roots fell substantially by August, recovering slightly by late October (Fig. 1A). However, in 2004, there was no peak in new root emergence during midsummer for any of the rootstocks. In fact, new root counts on the first observation date in May 2004 were the highest observed during that growing season for all 3 rootstocks (Fig. 1B). During the month after harvest in 2004, there was a moderate increase in new root emergence for all 3 rootstocks, but it was significantly higher than before harvest only for CG.6210 and M.7.

\section{Total (new and older) root counts}

The trends over time for total live (new and old) roots per rootstock were slightly different from those observed for new root emergence (Fig. 2). The total number of live roots was much greater in July than in May 2003, but total counts subsequently remained high and steady for all 3 rootstocks. The decrease in total root counts from July to August 2003 was significant only for G.30 (Fig. 2A). In 2004, total root counts remained relatively steady throughout the growing season, with a slight but significant decrease for all rootstocks the month before fruit harvest on 1 October 2004 (Fig. 2B).

\section{Cumulative (live and dead)} root demographics

The flush of new root emergence in July of 2003 comprised the majority of cumulative roots observed that year, accounting for more than $60 \%$ of the roots produced on all rootstocks (Fig. 3A). The initial root counts in May 2003 accounted for only $10 \%$ of subsequent total roots observed that year, whereas in 2004, the overwintering and early season root counts in May comprised $45 \%$ to $65 \%$ of the total roots for that year (Fig. 3B). Observed root disappearance over the winter between October 2003 and May 2004 averaged $83 \%$ for all rootstocks and ranged from $0 \%$ to $100 \%$ root mortality among individual observation tubes. Of the live roots observed in the initial observations in May 2004, 33\% were overwintered survivors from the previous year. Differences in cumulative rootcount percentages between the 2 years were significant, but within each year, trends were similar among the 3 rootstocks.

\section{Median root lifespans each year}

During 2003, median root lifespans for the initial fine root (diameter $<2 \mathrm{~mm}$ ) cohort present at the first observations in May ranged from 50 days for $\mathrm{G} .30$ to 70 days for M.7, but these differences were not statistically significant (Fig. 4A). Under similar soil conditions but with a fruit crop on all trees in 2004, fine root median lifespans were 35 days for G.30, 45 days for M.7, and 95 days for CG.6210 (Fig. 4B). Using M.7 as the reference rootstock, a Cox proportional hazards regression analysis demonstrated that G.30 and M.7 had significantly shorter median root lifespans than CG.6210 during 2004 (Table 2 ). Within the same root cohorts in May 2004 , roots below 20-cm depth had longer lifespans than roots in the 0 - to 20 -cm depth interval (Table 2; Fig. 5). Root diameter influence on lifespan was not statistically significant, perhaps because there were so few large diameter roots $(>0.3 \mathrm{~mm})$ (Fig. 5). Root diameter distribution patterns were similar among different root depth intervals (data not shown).

\section{Root depth distribution}

Root counts at each depth interval differed among rootstocks and over the growing seasons each year (Fig. 6). The deepest roots observed under any trees were at $35 \mathrm{~cm}$ depth in 2003 and at $39 \mathrm{~cm}$ depth in 2004. Trees on CG.6210 rootstocks had more roots at shallow depths in May 2003, and more deep roots throughout 2004, compared with the other 2 rootstocks. Trees on G.30 had more roots at 16- to $20-\mathrm{cm}$ depth than the other rootstocks in May 2003 and more roots at 6- to $10-\mathrm{cm}$ depths in May 2004. Trees on M.7 had more roots at 11 to $20 \mathrm{~cm}$ depth in May and September 2004 and more roots at 6 to 10 cm depth in July 2004 compared with the other rootstocks. During the period of maximum new root emergence in July 2003, there were relatively more roots at $10-$ to $30-\mathrm{cm}$ depths 

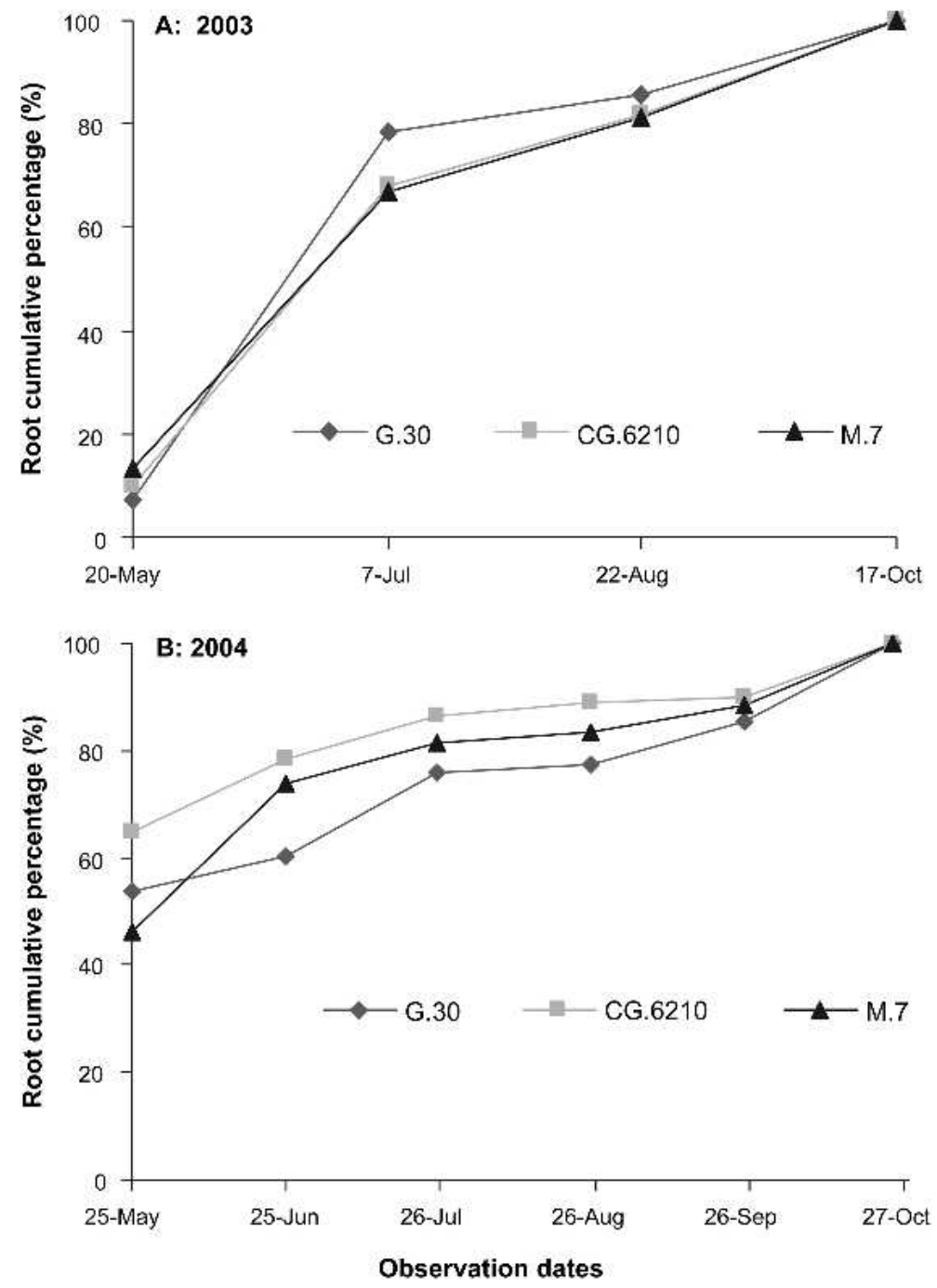

Fig. 3. Cumulative total root percentages (live and dead) of 18 observations on each date for each rootstock during growing seasons of 2003 and 2004.

than shallower or deeper for all 3 rootstocks and no differences among rootstocks.

\section{Above-ground tree performance on different rootstocks}

The above-ground differences in tree growth and fruit yields were consistently different among the 3 rootstocks and did not closely reflect trends in below-ground root growth or demographics. Trees on CG.6210 had more trunk diameter growth than trees on the other 2 rootstocks during all 3 years of observations (Table 3). Central leader extension growth was greatest on CG.6210 during 2002 but similar for all 3 rootstocks in 2003 (it was not measured in 2004). Trees on M.7 rootstocks produced less lateral extension growth than those on CG.6210 and G.30 rootstocks in 2003 when there was no crop present, but the more heavily cropped trees on CG.6210 produced less lateral branch growth than those on the other 2 rootstocks during 2004.

The fruit counts and total fruit weights per tree were substantially different among the 3 rootstocks when the first crop was harvested in 2004 (Table 3). Trees on CG.6210 rootstocks yielded an average $26 \mathrm{~kg}$ of fruit compared with $18 \mathrm{~kg}$ on G.30 and $11 \mathrm{~kg}$ per tree on M.7. These yield trends were not just a function of differences in tree size, because the differences among rootstocks remained consistent when yield efficiency (as both weight and number of apples per unit of trunk cross-sectional area) was calculated (Table 3). By any measure, trees on CG.6210 yielded more than those on G.30 which in turn yielded more than those on M.7 rootstocks.

\section{Discussion}

The observed root-growth trends for our trees during their final nonbearing year (2003) and their first bearing year (2004) suggest that crop load can greatly suppress new root development in young apple trees (Fig. 1). Previous reports have indicated that heavy crop load suppressed root and shoot growth in apple, peach (Prunus persica [L.]
Batsch.), and pistachio (Pistacia vera L.) trees (Chen et al., 1997; Inglese et al., 2002; Pfammatter and Dessimoz, 1996; Rosecrance et al., 1996). Others have demonstrated that partitioning of carbon assimilates within fruit trees was affected by both crop load and rootstock genotype (Inglese et al., 2002; Lenz, 2001). For alternate-year-bearing pistachio in California, root growth was reduced during the heavy bearing year, but there was no apparent relationship between root growth and the uptake of $\mathrm{N}, \mathrm{P}$, or $\mathrm{K}$ from the soil (Rosecrance et al., 1996). In our experiment, fruit load decreased fine root growth and greatly reduced shoot extension growth in 2004, but these effects were not associated with differences in soil nutrient status among the preplant soil treatments or minor differences in leaf content of essential elements (Leinfelder and Merwin, 2006).

Hughes and Gandar (1993) reported that the soil volume occupied by apple roots and root length density reached a maximum in approximately 4 years. Year 2004 was the third leaf for our trees, but there were fewer roots observed in 2004 than 2003 at the soil interface around minirhizotron tubes. We could not estimate total root dry matter accumulation because we did not excavate and weigh root systems, but our data suggest that carbohydrate competition from fruits and shoots can severely limit root growth in young bearing apple trees.

The major root growth peak that occurred between late May and July 2003 was consistent with previous reports for lightly cropped young 'Mutsu' trees on M.9 rootstock (Psarras et al., 2000) or mature 'Empire' on M.9 rootstock (Li et al., 2003), and this root growth peak coincided with the major growth phase of shoots and fruitlets. Atkinson (1980) reported that apple roots can have one to several annual growth peaks depending on climate, soil conditions, cultural practices, and scion or rootstock genotypes. Psarras et al. (2000) noted that cold and waterlogged soil conditions delayed new root growth in spring, and the decline in new root emergence that we observed after July 2003 coincided with a period of unusually cool and wet weather at our test site. It is likely that root growth patterns in this orchard reflected the combined effects of crop load, rootstock genotypes, climate, and soil conditions.

Root lifespans differed much more among rootstocks in the first bearing year (2004) compared with the last nonbearing year (2003) in our study (Fig. 4). Previously reported median root lifespans of apple trees have ranged from 14 days (Head, 1966) up to 114 days (Eissenstat and Yanai, 1997; Li et al., 2003; Psarras et al., 2000; Wells and Eissenstat, 2001). This reported variation may be partly the result of the different criteria used by various researchers to assess root mortality. In Head's (1966) research, root lifespan referred to the length of time that roots remained white, which could underestimate root lifespan compared with using disappearance as the criterion for root death (Eissenstat and Yanai, 1997). Browning 

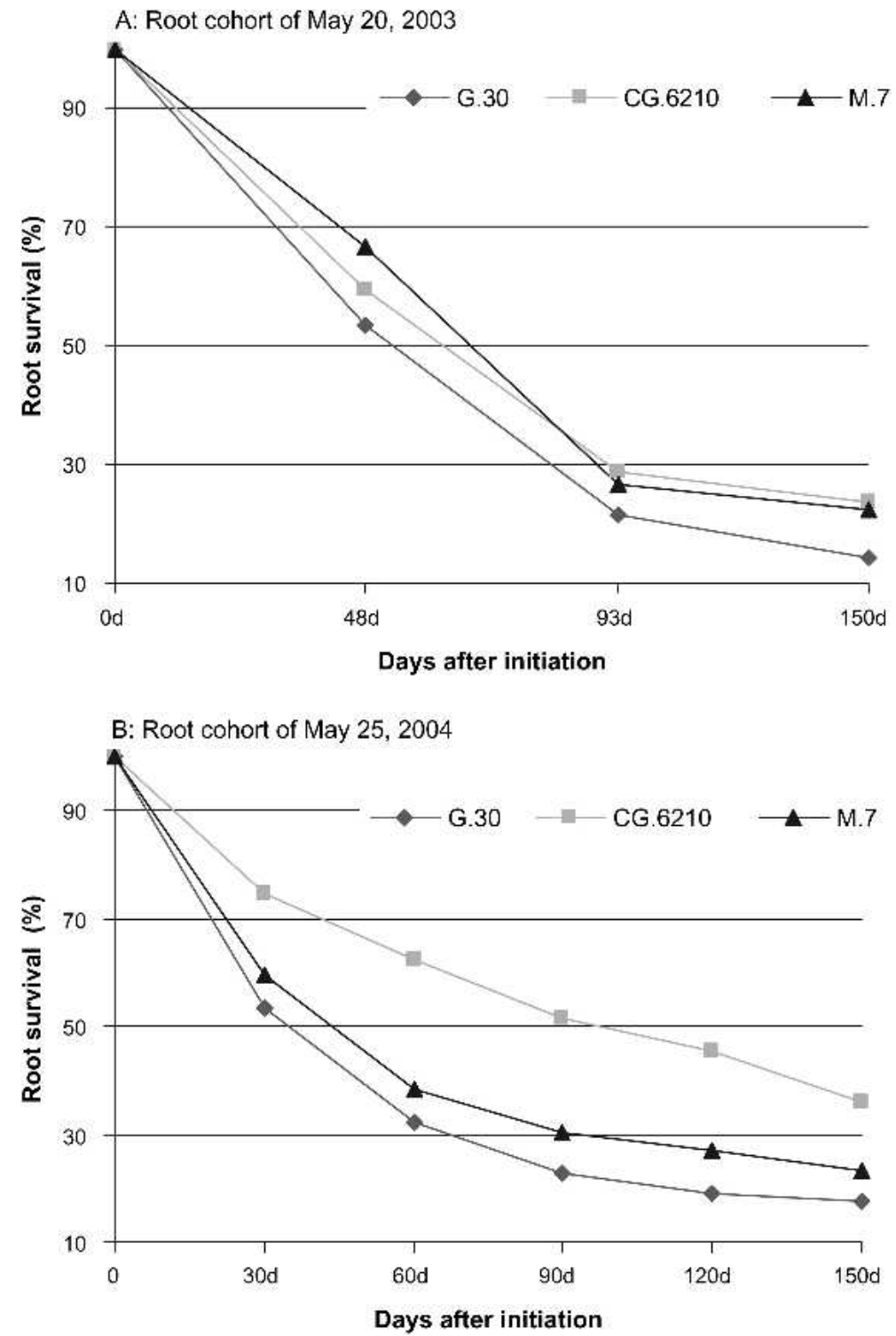

Fig. 4. Survival of roots from the initial fine root ( $<2 \mathrm{~mm}$ diameter) cohort observed in May 2003 (A) and 2004 (B) for 3 clonal rootstocks (CG.6210, G.30, and M.7) during subsequent growing seasons each year.

per se is not a reliable indicator of root death in apple, because up to $90 \%$ of brown roots can remain vital (Wells and Eissenstat, 2001) as observed in previous and the present studies. We also note that as a result of the 30- to 45-day intervals between our observations, there may have been some fine roots that initiated and then disappeared between sequential monthly observations.

Roots produced early in the growing season may have shorter lifespans than those produced later in the growing season (Head, 1966). Deciduous forest trees and citrus reportedly have longer root lifespans than fruit trees (Kosola and Eissenstat, 1995; Pregitzer et al., 1993). Surface roots $(0-10 \mathrm{~cm})$ of cherry had significantly shorter median lifespan than roots at deeper depth (Baddeley and Watson, 2005). The longer lifespan of roots produced by CG.6210 in our study could be the result of the deeper distribution of its roots Figs. (5A) and 6 and may also represent a physiological response that reduces carbon losses. Because of CG.6210s heavy crop load in 2004 assimilate that would otherwise have been required for root growth may have been available to support that increased fruit production. If existing roots could survive and function longer to meet the requirements of fruit development, this would help to compensate for fewer new roots and support the metabolic demands of crop load.

Despite the substantial reduction in new root growth and high crop demand for nutrients during 2004, there were negligible differences in leaf nutrient concentrations during any year of our study (Leinfelder and Merwin, 2006). Foliar nutrient values remained within recommended sufficiency ranges for trees on all 3 rootstocks and in all of the preplant soil treatments (Stiles et al., 1991). A similar lack of correlation between pistachio root growth and $\mathrm{N}, \mathrm{P}$, and $\mathrm{K}$ assimilation was reported by Rosecrance et al. (1996). The nutrient contents of leaves from trees on different rootstocks differed little in our study during either the 2 first vegetative years after planting or the first bearing year. This suggests that essential root function in apple trees is not closely coupled with root density or age, because 3 rootstocks with very different demographic traits were equally capable of supplying adequate elemental nutrients to the above-ground portions of trees in our study.

Almost all of the roots encountering our minirhizotron tube surfaces were $<2 \mathrm{~mm}$ diameter, with the majority $<1 \mathrm{~mm}$ (data not shown). Hence, most of our observations were related to the fine feeder roots that are most important for assimilation of essential nutrients from soil (Atkinson, 1980). However, these feeder roots diverge from more persistent major roots, and thus observed fine root distribution and demography should reflect indirectly that of the whole root system.

Apple root distribution at various soil depths is influenced by management practices and soil characteristics (Atkinson, 1980). Root systems are generally more extensive horizontally than fruit tree branches spread (Rogers, 1939), but the likelihood of encountering roots is greatest in a relatively small zone horizontally and vertically near the trunk, especially when weeds are suppressed by herbicides (Atkinson et al., 1976). In situ root observations and fine scale excavations are technically very challenging (Eissenstat and Yanai, 1997). Despite recording and analyzing almost 60,000 root images for this study, we encountered the usual difficulties attaining sample sizes sufficient to compensate for the high variance of root distribution. This situation makes statistical analyses of root observational data problematic.

Previous excavation studies (Atkinson, 1980) showed that apple roots could extend from 0.4 to $8.6 \mathrm{~m}$ deep, but approximately $70 \%$ of total root biomass occurred at 0 to $30 \mathrm{~cm}$ depth, and root distribution was influenced by rootstock genotype, age, soil type, planting density, soil management, and cultural factors. In an earlier study near our present site, Psarras et al. (2000) reported that most of the fine roots on M.9 rootstock were in the upper $25-\mathrm{cm}$ soil profile. The root depth distribution of M.7 in our study was similar to these previous reports, but the root systems of G.30 and CG.6210 were deeper than M.7 or M.9 in other studies on similar soils. The deeper root distribution and greater root lifespan of CG.6210 could make this rootstock less affected by soil temperature and moisture variations, increasing root lifespan and access to deeper water and nutrient supplies that may enable its root system to support greater fruit tree growth and productivity.

To our knowledge, there have been no previous studies of apple root distribution and demographics for various rootstocks in different preplant soil treatments at an ARD site. In related studies at our planting, DNA 

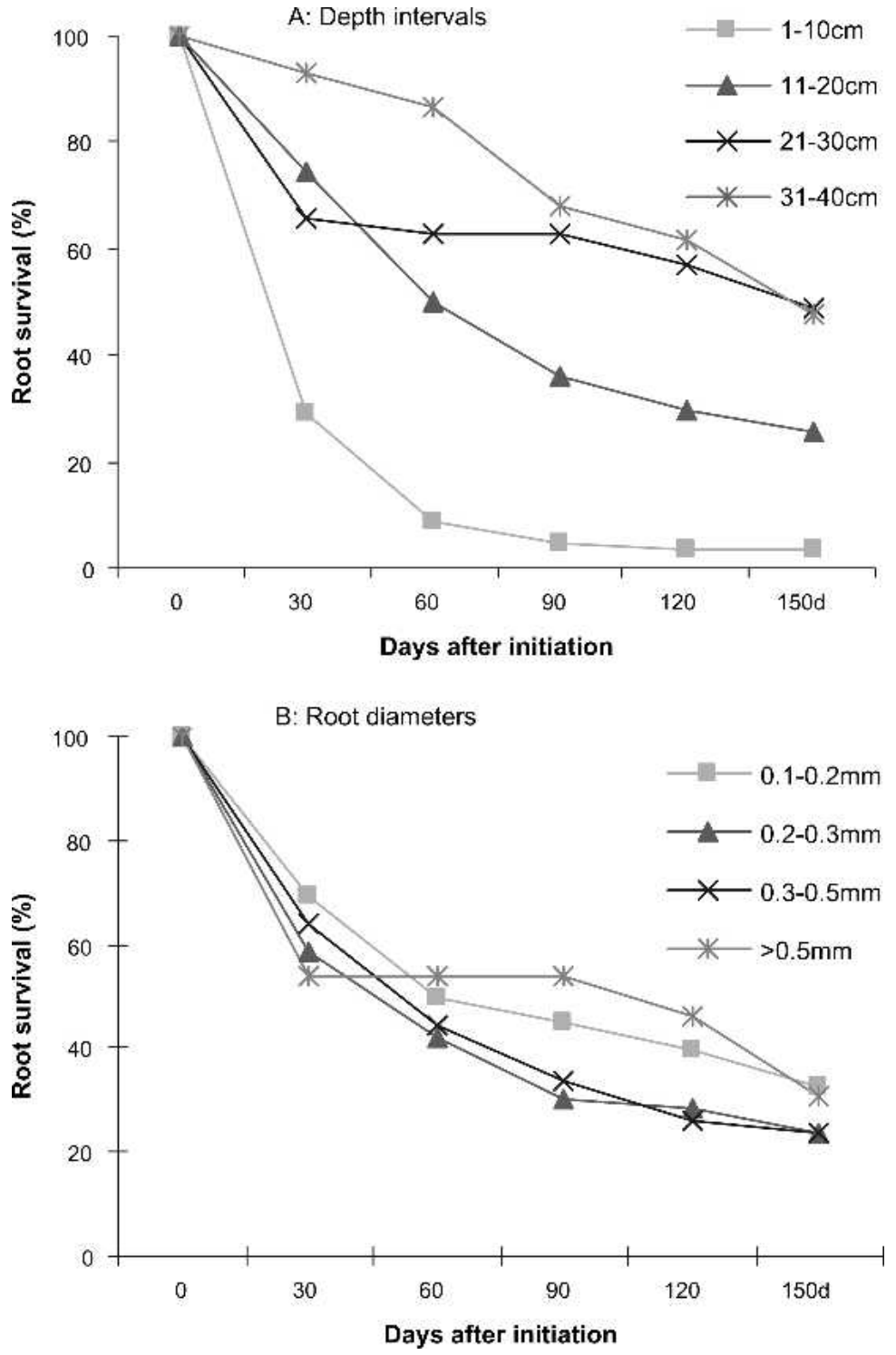

Fig. 5. Survival of roots from 25 May 2004 cohort for different depth (A) or diameter (B) categories, with all 3 rootstocks combined, during the subsequent growing season.

Table 2. Results of Cox proportional hazards regressions for apple rootstocks in relation to the covariates of rootstock, root depth, and root diameter ${ }^{\mathrm{z}}$.

\begin{tabular}{lcccc}
\hline Covariate & Cox regression coefficient & Standard error & $P$ value & Hazard ratio \\
\hline Rootstock & & & & \\
(reference = M7) & -0.416 & -2.186 & 0.0288 & 0.660 \\
CG6210 & 0.213 & 1.206 & 0.2280 & 1.237 \\
CG30 & -0.355 & -0.821 & 0.4119 & 0.701 \\
Diameter & & & & \\
& & & & \\
Depth & & & & \\
(reference =40 cm) & 1.508 & 6.075 & $<0.0001$ & 1.926 \\
$10 \mathrm{~cm}$ & 0.655 & 2.715 & 0.0066 & 1.158 \\
$20 \mathrm{~cm}$ & 0.147 & 0.465 & 0.6417 & \\
$30 \mathrm{~cm}$ & & & & \\
\hline
\end{tabular}

${ }^{\mathrm{z}}$ Hazard ratios of categorical covariates are the risk of death relative to a reference level. Thus, a risk ratio significantly higher than 1.0 indicates that roots of that category (rootstock, diameter class, or depth interval) were more likely to die than the reference level.

Table 3. Tree growth and yield on different clonal rootstocks in an apple replant site from 2002 to $2004^{z}$. fingerprint analyses of fine root samples and rhizosphere soil samples revealed that preplant soil treatments altered microbial community composition and function, but rootstock genotype was still the most important determinant for microbial communities in the rhizosphere (Rumberger et al., 2004; Yao et al., 2006). We did not conduct microscopic or differential stain analyses of root samples from trees in this study, but when roots were viewed through the low magnification of our rhizotron camera lens, we did not detect consistent differences in the color, texture, diameter or general appearance of roots on the 3 rootstock clones despite their different median lifespans, rooting depth, and associated rhizosphere microflora. It is possible that the characteristic rhizosphere microbial communities on different rootstocks are an important factor in tree performance and root function in replant orchards, and additional research is underway to test this hypothesis. Whatever the underlying physiological mechanisms or microbial relationships may be, our study indicates that some new ARD-resistant or -tolerant rootstock clones may provide a robust root system that supports rapid tree establishment and early onset of fruit production without the need for preplant soil fumigation or other soil amendments at replant orchard sites.

\section{Literature Cited}

Agnello, A.M., A.J. Landers, W.W. Turechek, D.A. Rosenberger, T.L. Robinson, J.R. Shupp, J.E. Caroll, L. Cheng, P.D. Curtis, D.I. Breth, and S.A. Hoying. 2002. Pest management guidelines for commercial tree-fruit production. Cornell Cooperative Extension, Ithaca, N.Y.

Atkinson, D. 1980. The distribution and effectiveness of the roots of tree crops. Hort. Rev. (Amer. Soc Hort Sci) 2:424-490.

Atkinson, D., D. Naylor, and G.A. Coldrick. 1976. Effect of tree spacing on apple root-system. Horticultural Research 16:89-105.

Baddeley, J.A. and C.A. Watson. 2005. Influence of root diameter, tree age, soil depth and season on fine root survivorship in Prunus avium. Plant Soil 276:15-22.

Chen, K., G.Q. Hu, and F. Lenz. 1997. Biomass partitioning in apple trees as affected by training, shading, and fruiting. Gartenbauwissenschaft 62:162-168.

Geldart, H.G. 1994. The impact of replant problems on the economics of high density apple plantings. Acta Hort. 363:11-18.

Eissenstat, D.M. and R.D. Yanai. 1997. The ecology of root lifespan, 1-60. Advances in Ecological Research. Vol 27. Academic, London.

Eissenstat, D.M., C.E. Wells, R.D. Yanai, and J.L. Whitbeck. 2000. Building roots in a changing environment: implications for root longevity. New Phytol. 147:33-42.

\begin{tabular}{|c|c|c|c|c|c|c|c|c|c|c|}
\hline & \multicolumn{3}{|c|}{ Caliper (mm) } & \multicolumn{2}{|c|}{$\begin{array}{l}\text { Central extension } \\
\text { growth }(\mathrm{cm})\end{array}$} & \multicolumn{2}{|c|}{$\begin{array}{l}\text { Lateral extension } \\
\text { growth }(\mathrm{cm})\end{array}$} & \multicolumn{3}{|c|}{ Yield 2004} \\
\hline & 2002 & 2003 & 2004 & 2002 & 2003 & 2003 & 2004 & Count tree $^{-1}$ & $\mathrm{~kg}$ tree $^{-1}$ & Fruit counts $\mathrm{cm}^{-2}(\mathrm{TCSA})$ \\
\hline$\overline{\text { CG.6210 }}$ & $16.5 \mathrm{a}$ & $31.0 \mathrm{a}$ & $35.6 \mathrm{a}$ & $84.6 \mathrm{a}$ & $72.7 \mathrm{a}$ & $79.4 \mathrm{a}$ & $20.0 \mathrm{~b}$ & $153 \mathrm{a}$ & $26.1 \mathrm{a}$ & $15.4 \mathrm{a}$ \\
\hline G.30 & $14.5 \mathrm{~b}$ & $25.8 \mathrm{~b}$ & $31.2 \mathrm{~b}$ & $66.6 \mathrm{~b}$ & $74.5 \mathrm{a}$ & $80.9 \mathrm{a}$ & $26.1 \mathrm{a}$ & $101 \mathrm{~b}$ & $17.7 \mathrm{~b}$ & $12.3 \mathrm{~b}$ \\
\hline M.7 & $14.1 \mathrm{~b}$ & $25.7 \mathrm{~b}$ & $30.7 \mathrm{~b}$ & $66.4 \mathrm{~b}$ & $73.5 \mathrm{a}$ & $71.7 \mathrm{~b}$ & $25.5 \mathrm{a}$ & $63 \mathrm{c}$ & $11.1 \mathrm{c}$ & $8.8 \mathrm{c}$ \\
\hline
\end{tabular}

${ }^{\mathrm{z}}$ Data from Leinfelder and Merwin, 2006. Means followed by different letters were significantly different at $P=0.05$. 

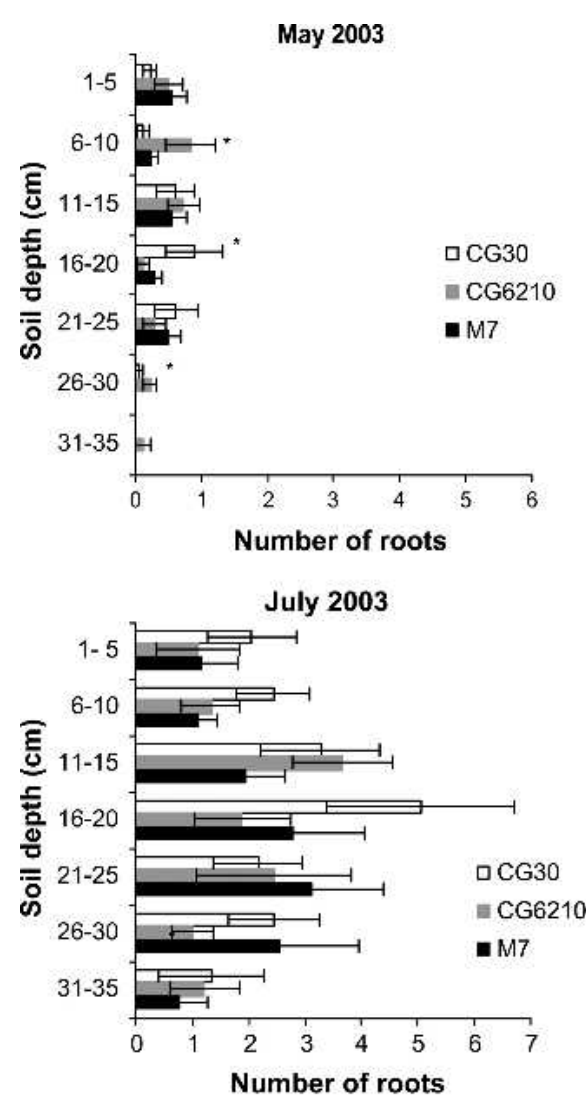

October 2003

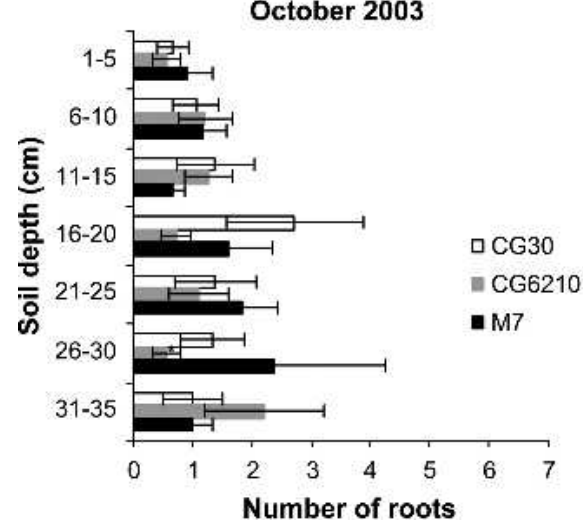

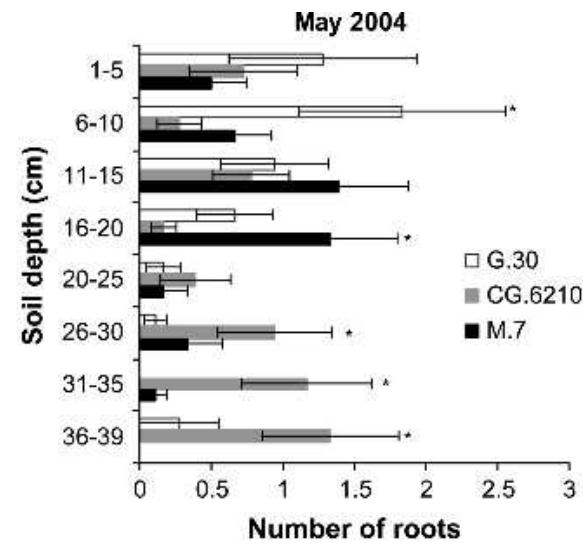

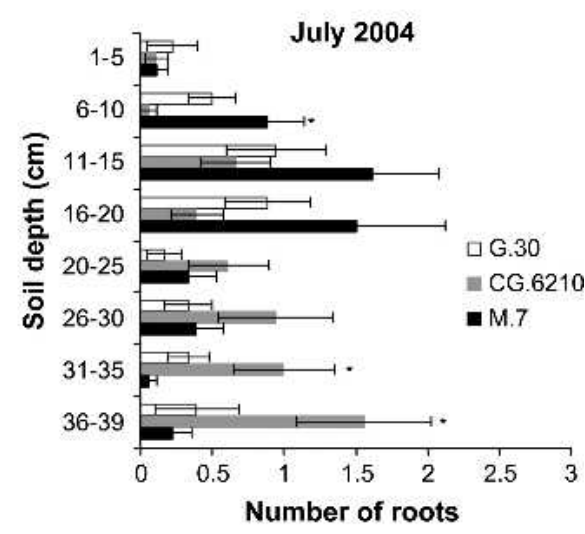

Sept. 2004

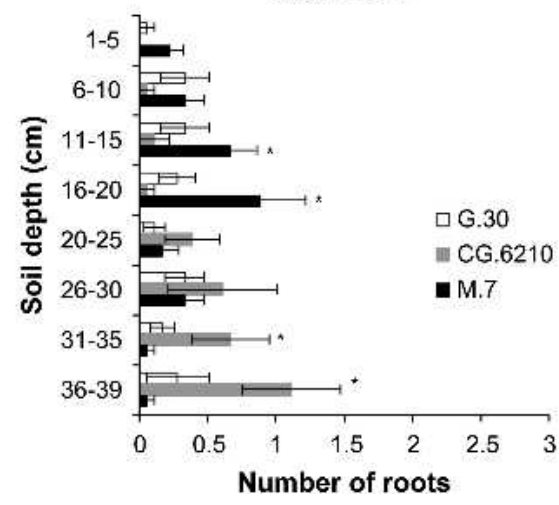

Fig. 6. Depth distributions of live roots at 5-cm intervals for the rootstocks CG.6210, G.30, and M.7 during 2003 and 2004. Values are the average of 18 observations (tubes) for each rootstock, \pm standard error of mean. The asterisks indicate significant differences among rootstocks $(P=0.05)$ within each depth interval.

Head, G.C. 1966. Estimating seasonal changes in the quantity of white unsuberized root on fruit trees. J. Hort. Sci. 41:197-206.

Hendrick, R.L. and K.S. Pregitzer. 1992. The demography of fine roots in a northern hardwood forest. Ecology 73:1094-1104.

Hendrick, R.L. and K.S. Pregitzer. 1993. Patterns of fine root mortality in two sugar maple forests. Nature 361:59-61.

Hughes, K.A. and P.W. Gandar. 1993. Length densities, occupancies and weights of apple root systems. Plant Soil 148:211-221.

Inglese, P., T. Caruso, G. Gugliuzza, and L.S. Pace. 2002. Crop load and rootstock influence on dry matter partitioning in trees of early and late ripening peach cultivars. J. Amer. Soc. Hort. Sci. 127:825-830.

Isutsa, D.K. and I.A. Merwin. 2000. Malus germplasm varies in resistance or tolerance to apple replant disease in a mixture of New York orchard soils. HortScience 35:262 268.

Kosola, K.R. and D.M. Eissenstat. 1995. Root demography of mature citrus trees: the influence of Phytophthora nicotianae. Plant Soil 171:283-288.

Leinfelder, M. and I. Merwin. 2006. Rootstock selection, pre-plant soil treatments, and tree planting positions as factors in managing apple replant disease. HortScience 41:394401.

Lenz, F. 2001. Roots of dwarfed apple trees as affected by fruit load, water and nutrient supply and pruning date. Apple rootstocks for inten- sive orchards Proceedings of the International SeminarWarsaw-Ursynow, Poland. 18-21, Aug. 1999. pp. 13-14.

Li, K.T., A.N. Lakso, R. Piccioni, and T. Robinson. 2003. Summer pruning effects on fruit size, fruit quality, return bloom and fine root survival in apple trees. J. Hort. Sci. Biotechnol. 78: 755-761.

Mai, W.F. and G.S. Abawi. 1981. Controlling replant diseases of pome and stone fruits in northeastern United States by preplant fumigation. Plant Dis. 65:859-864.

McKenry, M., T. Buzo, J. Kretsch, S. Kaku, E. Otomo, R. Ashcroft, A. Lange, and K. Kelley. 1994. Soil fumigants provide multiple benefits; alternatives give mixed results. Calif Agr. 48:22-28.

Merwin, I.A., R. Byard, T.L. Robinson, S. Carpenter, S.A. Hoying, K.A. Iungerman, and M. Fargione. 2001. Developing an integrated program for diagnosis and control of replant problems in New York apple orchards. New York Fruit Quarterly 9:11-15.

Pfammatter, W. and A. Dessimoz. 1996. Influence of different crop loads on development, photosynthesis and dry matter production of young Maigold apple trees. Revue Suisse de Viticulture, d'Arboriculture et d'Horticulture 28: 247-250.

Pregitzer, K.S., R.L. Hendrick, and R. Fogel. 1993. The demography of fine roots in response to patches of water and nitrogen. New Phytol. $125: 575-580$

Psarras, G., I.A. Merwin, A.N. Lakso, and J.A. Ray. 2000. Root growth phenology, root longevity, and rhizosphere respiration of field grown 'Mutsu' apple trees on 'Malling 9' rootstock. J. Amer. Soc. Hort. Sci. 125:596-602.

Rogers, W.S. 1939. Root studies VII. Apple root growth in relation to rootstock, soil, seasonal and climatic factors. J. Pomol. Hort. Sci. 17: 99-130.

Rosecrance, R.C., S.A. Weinbaum, and P.H. Brown. 1996. Assessment of nitrogen, phosphorus, and potassium uptake capacity and root growth in mature alternate-bearing pistachio (Pistacia vera) trees. Tree Physiol. 16:949956.

Rumberger, A., S. Yao, I.A. Merwin, E.B. Nelson, and J.E. Thies. 2004. Rootstock genotype and orchard replant position rather than soil fumigation or compost amendment determine tree growth and rhizosphere bacterial community composition in an apple replant soil. Plant Soil 264:246-260

Stiles, W.C. and W. Reid. 1991. Orchard nutrition management. Cornell Coop. Ext. Bul 219, Ithaca, N.Y., $19 \mathrm{pp}$.

Wells, C.E. and D.M. Eissenstat. 2001. Marked differences in survivorship among apple roots of different diameters. Ecology 82:882892.

Wells, C.E. and D.M. Eissenstat. 2003. Beyond the roots of young seedlings: the influence of age and order on fine root physiology. J. Plant Growth Regul. 21:324-334.

Wilton, J. 2002. Orchard redevelopment in New Zealand. The Compact Fruit Tree. 35:122125.

Yao, S., I.A. Merwin, G.S. Abawi, and J.E. Thies. 2006. Apple rootstocks and pre-plant soil treatments alter soil microbial community composition in a replant New York orchard. Soil Biol. Biochem. 38:587-599. 